\title{
Developing Interaction in ESL Classes: An Investigation of Teacher-Student Interaction of Teacher Trainees in a Sri Lankan University
}

\author{
Abdul Majeed Mohamed Navaz \\ South Eastern University of Sri Lanka, Sri Lanka \\ https://orcid.org/0000-0003-2042-652X
}

\begin{abstract}
This study examines the possibility of using of IRF (InitiationResponse-Follow-up) sequence of teacher-student interaction in Sri Lankan ESL (English as a Second Language) classes for developing longer interactional exchanges which are believed to be useful for language development. Usually, in Sri Lankan ESL classes, teachers ask more display questions and a few referential questions. As a result, teacher-student interaction occurs only occasionally and they follow the traditional IRF pattern with an evaluation at the third move. Teachers could develop longer interactional exchanges by giving follow-up questions or prompts at the third move of the IRF sequence so that students respond, elaborate, explain or prolong their responses. This study examines how the teacher trainees on their teaching practice of a TESL degree programme at a university interacted with their students in ESL classes and how they changed their pattern of interaction to sustain more student interaction. Using lecture discourse data as the basis of the analysis, this study evaluated the changes after an intervention that focussed on training the teacher trainees in developing longer interactional episodes. The results revealed that there was only a slight improvement in the way teacher trainees maintained interactions in the lessons after the intervention. Hence, this study enlightens the possibility of utilizing interaction for language development through intensive teacher training.
\end{abstract}

Keywords: questions; ESL classes; interaction; IRF; teacher trainees

\section{Introduction}

English language proficiency of students at secondary and tertiary levels in Sri Lanka has been a concern for legislators and educational administrators. A tracer study conducted by the University Grants Commission in 2018 on graduate employment reports that only around $27 \%$ of the graduates from the Faculty of Arts of the university, where this study was conducted, were employed. Lack of employment has always been connected to lack of language proficiency of the graduates. It is believed that language proficiency of students, 
especially the speaking skills, could be developed by giving opportunities to speak in the ESL classes. In other way, teachers could handle the classroom discourse to provide opportunities for students to speak.

It is generally claimed that students in Asian countries are reluctant to speak in the classroom. A previous study by the researcher (Navaz, 2012) in undergraduate content classes in the same university revealed that students rarely asked or answered questions. To improve the situation, based on the theory of output hypothesis proposed by Swain (1995), it is argued that students should be given opportunities to speak in the class. However, the tendency in Sri Lankan ESL classes at secondary and tertiary levels is that teacher talk occupies most of the class time. Recent peer observation by the researcher of a class conducted by an instructor at the faculty revealed that around $90 \%$ of his class time was occupied by teacher talk (Semester II, 2018/2019 academic year, Quality Assurance Process).

While limited interaction in ESL classes could be connected to various reasons, in this study, developing the classroom interaction has been considered as an alternative to developing the language proficiency of students. A few instances of teacher-student interactions in the study context, as exist in several other contexts, followed the traditional three-part exchange, IRF, which consists of a question, known as Initiation (I), followed by an answer, called Response (R) and the last step is a Follow-up by the teacher $(\mathrm{F})$. Teachers initiate teacherstudent interaction by asking a question (Initiation - I) in a one-to-one situation (or sometimes, the first question is directed to the whole class), and the students respond to that (Response - R) question. This is followed by a follow-up (Follow-up - F) that can be a feedback. This pattern was identified by Sinclair and Coulthard (1975) as IRF pattern, whereas Mehan (1979) proposed it as IRE pattern, where the last move was 'Evaluation' instead of a 'Feedback'. In this study, 'IRF' generally refers to a 'Follow-up' at the last move unless specified as feedback, while 'IRE' refers to an evaluation at the end position.

Despite the fact that IRF pattern has been a dominant type of discourse structure in ESL as well as content classes, which is also deemed to be limiting students' participation in classroom discourse, there are possibilities that teachers could make use of the last move by providing feedback so that they can sustain longer meaningful interactions that are useful for language development of students in ESL classes (Walsh, 2011). That is, teachers should make use of the last move of a three-part exchange to give a follow-up question/comment (e.g. can you explain further?) to students instead of an evaluation (e.g good or OK). The follow-up questions as feedback help clarify learners' contributions and pronunciation (Chang, 2009) so that the discourse could be prolonged. Recently, the focus has been shifted towards students' construction of knowledge along with language development in content classes (e.g. Chin, 2007; Yip, 2004). Hence, several other research studies have examined the possibility of extending the teacher-student interaction beyond IRF sequence. For example, Cullen (2002), Lee (2007), Waring (2009), Skinner (2019), etc. have been discussed in the literature review section. 
In the study context, the opportunities to learn English language for the students are confined to ESL classes only. The students in the faculty receive only a few hours of instruction in teacher-fronted classrooms. Hence, this study unearths the possibilities of developing students' ability to interact in ESL classes in the faculty where students learn English as a second language while studying their academic studies in their mother tongue, Tamil. On the basis of the argument that teacher-student interaction which involves students in constructive dialogue in ESL classes would help develop language proficiency of the learners (Gibbons, 2003; Gibbons, 2015; Gupta \& Lee; 2015; Hall \& Verplaetse, 2000; Haneda, 2005; Haneda \& Wells, 2010), this study attempts to examine the existing pattern of interaction in ESL classes and the possibilities of developing interaction by manipulating teacher controlled IRF sequences. In the absence of notable previous studies either in Sri Lanka or South East Asia on classroom discourse, this study could be considered important for trying to unearth an important area of classroom discourse which could be useful for developing the language proficiency of the students who are already deemed to be in a disadvantaged position in terms of employment opportunities for which lack of language proficiency is considered to be one of the reasons.

Teachers in Sri Lankan content classes rarely move beyond this IRF pattern of discourse for the reason that they are not aware of the techniques of moving beyond IRF nor are they concerned about the importance of extending the interaction, as was revealed in a previous study by the researcher in content classes (Navaz, 2012). Hence, studies in Sri Lankan ESL classroom discourse have been limited. Of the few studies conducted in Sri Lanka, Sanmuganathan (2017) claimed that most of the time ESL students and teachers use mother tongue to involve in interactions, while Samaranayake (2016) reported that the instructional method used by the ESL teachers did not provide opportunities for developing the speaking skills. His study was conducted in rural schools in Sri Lanka. Karunaratne (2003) also found that the methods used by the teachers in urban schools did not provide opportunities for language learning. Perera (2001) for her doctoral study investigated the role of interaction and use of textbooks for developing language proficiency in secondary level classes. Her study revealed that teacher-student interaction is not taking place at a satisfactory level.

The studies in Sri Lankan context reveal that teacher-student interaction does not take place in the ESL classrooms for various reasons. These studies focused on different factors like the teaching methods or textbooks used, etc. but no studies so far have looked into how the discourse could be handled by teachers to develop teacher-student interaction.

At the backdrop of the argument that the knowledge of IRF pattern and extending the IRF pattern is helpful for developing the interaction in classrooms, this study, involving the selected final year TESL (Teaching English as a Second Language) students on teaching practice (hereinafter referred to as Teacher Trainees -TTs) investigates what types of interaction the teacher trainees develop in ESL classes in the faculty and what impact an intervention focussing on training TTs to develop longer interactional exchanges has on classroom 
discourse. All the students who follow the TESL degree have to undertake teaching practice as part of the requirements of the course. In addition, this study examines the underlying reasons for the patterns of classroom discourse. In the absence of studies that deal with classroom interaction with a focus on classroom discourse in tertiary level ESL classes in Sri Lanka, the present study is considered important.

Hence, this study has the following research questions.

\subsection{Research questions}

RQ1. What types of interactional episodes do the teacher trainees develop before the intervention in the undergraduate ESL classes at the faculty and what are the underlying reasons?

RQ2: What impact does the intervention have on classroom discourse of ESL classes conducted by the TTs and what are the underlying reasons?

The next section describes the literature pertaining to the studies that dealt with classroom interaction in both content and ESL classes and the review looks into how the classroom discourse of traditional IRF/IRE pattern changes into longer meaningful interactional episodes with the use of 'follow-up'.

\section{Literature review}

\subsection{IRF in classroom discourse}

This study arises on the premise that teacher-student interaction which involves students in constructive dialogue in ESL classes would help develop language proficiency of the learners. It has long been established that teacher-student interaction is important in creating a suitable learning environment and for learners' language development (Hall \& Verplaetse, 2000). Hence, it helps develop the second language (Gibbons, 2003; Gibbons, 2015; Gupta \& Lee; 2015, Haneda, 2005; Haneda \& Wells, 2010). When the interaction is a recitation script with one-to-one question and answer sequences between teacher and students, the outcome of language development would be a question. When the ESL or content classroom talk is dialogic with mutual contributions from both students and teacher, it can be a good platform for content and language learning (Swain \& Lapkin, 1998). Swain (1995) also argues that students should get opportunities to practise the language to become fluent in the language. She proposed this argument through her 'output hypothesis' which regards conversational interaction as an 'excellent opportunity for developing speaking' (p. 248).

It is a widely accepted fact that classroom discourse of teacher-students in Sri Lanka as well as in other parts of the world follows the traditional IRF pattern which is also called IRE when the third move becomes an evaluation instead of a feedback (Hall, 1998). The three-part exchange structure or the 'triadic dialogue' (I-R-F) (Lemke, 1985; 1990) is the most occurring pattern as well as a popular tool for analyzing the classroom discourse structure. Wells (1993) regards that around $70 \%$ of the classroom discourse could be accounted by this IRF pattern.

The IRF sequence, being the general pattern of classroom interaction in ESL as well as content classes, is being criticized as teacher-centred. Recently, attention 
has been paid to utilize the IRF sequence to enhance student participation. Despite the fact that the IRF sequence is highly teacher controlled, the discussions are underway on how the teachers could make use the IRF to sustain interaction in classes (Davidson \& Edwards-Groves, 2020; Hall \& Walsh, 2002; Musumeci, 1996). In the absence of studies connected to ESL classroom discourse in Sri Lanka, this study, along this argument, tries to identify the existing pattern of discourse in undergraduate ESL classes and examines the possibilities of training the teachers to make use of the IRF sequence to develop interaction. In this section, I review the studies that attempted to use the IRF sequence for developing interaction from different contexts.

The general argument is that the IRF pattern of exchanges could be manipulated by the teachers to get more student participation. That is, the three-part structure is an effective tool for guiding the students for learning (Mercer, 1995) on the premises that the last move could be handled by the teacher to bring in more student involvement and participation (Wells, 1993).

\subsection{Follow-up at the third move and its benefits}

Hall (1998) as well as Lee (2007) stated that the variation in the IRF pattern could create different abilities to participate, different learning opportunities, and different outcomes. Two moves become important here; one is the initiation or the questions teachers ask that decide the nature of the flow of interaction. The other one is the third move which is equally important because it decides whether the interaction continues or is brought to a halt (Lee, 2007). The third move could play different functions such as offering evaluation, feedback or follow-up on the students' second move. In the third move, teachers not only respond to whether the students' answers are correct, adequate or relevant but also, even for correct answers, teachers could ask students to elaborate, reformulate or defend their answers (ibid).

Lee (2007) analysed the three-turn exchanges of the discourse of college ESL courses produced by international and immigrant students in North American universities to identify how the third turns $(\mathrm{F})$ were used to sustain interaction with students. Lee considers that the teachers should make use of the third move, without limiting to evaluate students' responses, for different discourse purposes. Some of them could be "estimating what students know and what they do not know, discovering particular identities of their students and their problems, finding and repairing what becomes problematic in the second turns" (ibid: 1226).

The findings of Lee (2007) agree with Wells and Arouz (2006) as well as Nassaji and Wells (2000) who argue that it is important how the teacher handles the last move, the 'follow-up', which is believed to have the ability of generating sufficient interaction in the classroom. Their research was based on school level science content classes in Toronto. Nassaji and Wells identified six functional moves that the third turn displays: evaluation, justifications, counter-argument, clarification, meta-talk and action. They advise that teachers should avoid giving evaluation in the follow-up move that would possibly suppress students' participation; instead, they demonstrated, teachers could request, in the follow- 
up move, for "justifications, connections, or counter arguments and allow students to self-select in making their contributions" (p. 401).

In a study conducted in a community English programme in the United States, Waring (2009) demonstrated using the discourse collected from a single student during the homework feedback session that how moving away from the traditional IRF sequence could bring in more in-depth discussions. Similarly, Wong and Waring (2009) suggest that giving a feedback like 'very good' is not conducive for learning because the feedback brings the students' contribution to a halt. Instead, they advise the teachers to use 'pursuit' questions (e.g. why do you say that?) so that students could engage in the activity more. Here Wong and Waring use the name feedback for evaluation and pursuit questions for what others call follow-up questions.

Liu (2008) differentiated the discourse between two teachers and demonstrated the opportunity to develop language through the handling of IRF moves, especially the follow-up move. In his study conducted in Chinese language classrooms, one of the teachers valued student contributions by providing positive acknowledgements and reformulations. Liu claimed that this has promoted students' involvement and created effective language learning opportunities (ibid). Similarly, Hellermann (2003) showed that the effective handling of the 'F move' in the IRF pattern had a number of positive consequences for student participation and learning. His study was based on urban high school content classes.

Cullen (2002) considered the teachers' handling of follow-up move in the IRF sequence in a secondary school EFL classroom in Tanzania. He invented two kinds of F moves: Evaluative and Discoursal. Cullen regards that the latter type of $\mathrm{F}$ move could be useful for language development as it reformulates and elaborates on student contributions, and derives further initiating moves from them. This study reveals that teacher could handle the last move in the IRF sequence to prolong the teacher-student interaction and obtain more student participation.

Skinner (2019) in a study conducted with nine teacher trainees on their teaching practice for their TESOL degree programme found that when the trainee teachers asked display questions for which answer is already known, the classroom discussions were confined to IRF sequence. As a result of the study, Skinner suggests that teachers should use referential questions which require genuine answer from the students.

As Boyd and Markarian (2015) claim, to develop longer interaction, the teachers can ask for clarification or elaborations in the third move instead of an evaluation which usually brings the interactional exchange to a halt. This could occur through requests for clarifications and elaborations in the third move (Edwards-Groves, 2014).

One way the feedback could develop language development is it helps clarify learners' contributions and pronunciation. This could occur through repairs producing reformulations (Chang, 2009) that are corrections made by learners 
themselves when teacher makes them realize that their utterance is not understood by the teacher. It is already established that negotiated interaction between the learners and the teacher can enhance comprehension of the input and in turn lead to language development (Long, 1985). Further, Van Lier (2001) claims that when the initiation-response-feedback exchange moves beyond mere recitation and display, it helps scaffolding instruction, develops cognitive structures in the zone of proximal development, or assists learners to express themselves with maximum clarity.

Despite the different opinions, researchers generally agree that when the third move of the IRF is a follow-up instead of evaluation, the teacher could develop longer meaningful interactions in the classroom. That is, the IRF pattern could be used for better student contribution by handling the last move ' $\mathrm{F}$ ' effectively (e.g. Hall, 1998; Lee, 2007; Nassaji \& Wells, 2000). In this way, teachers could maintain dialogic interaction in their classrooms too.

As indicated in Lemke's triadic dialogue, usually in classrooms a teacher's question receives a response from the students, and the teacher evaluates the student's response to end the exchange. This could be followed by another initiation by the teacher. Even though researchers (e.g. Wood, 1992) have earlier questioned the usefulness of this triadic dialogue, now it has been realised that these triadic dialogues could be used in a fruitful way by giving follow-up (e.g. feedback) instead of an evaluation (E) to make meaningful, connected interactional episodes between teacher and students (e.g. Nassaji \& Wells, 2000). This study also looks into the possibility of extending beyond the IRF pattern by asking follow-up questions at the last move. The conceptual framework of the study is given in Figure 1 below.

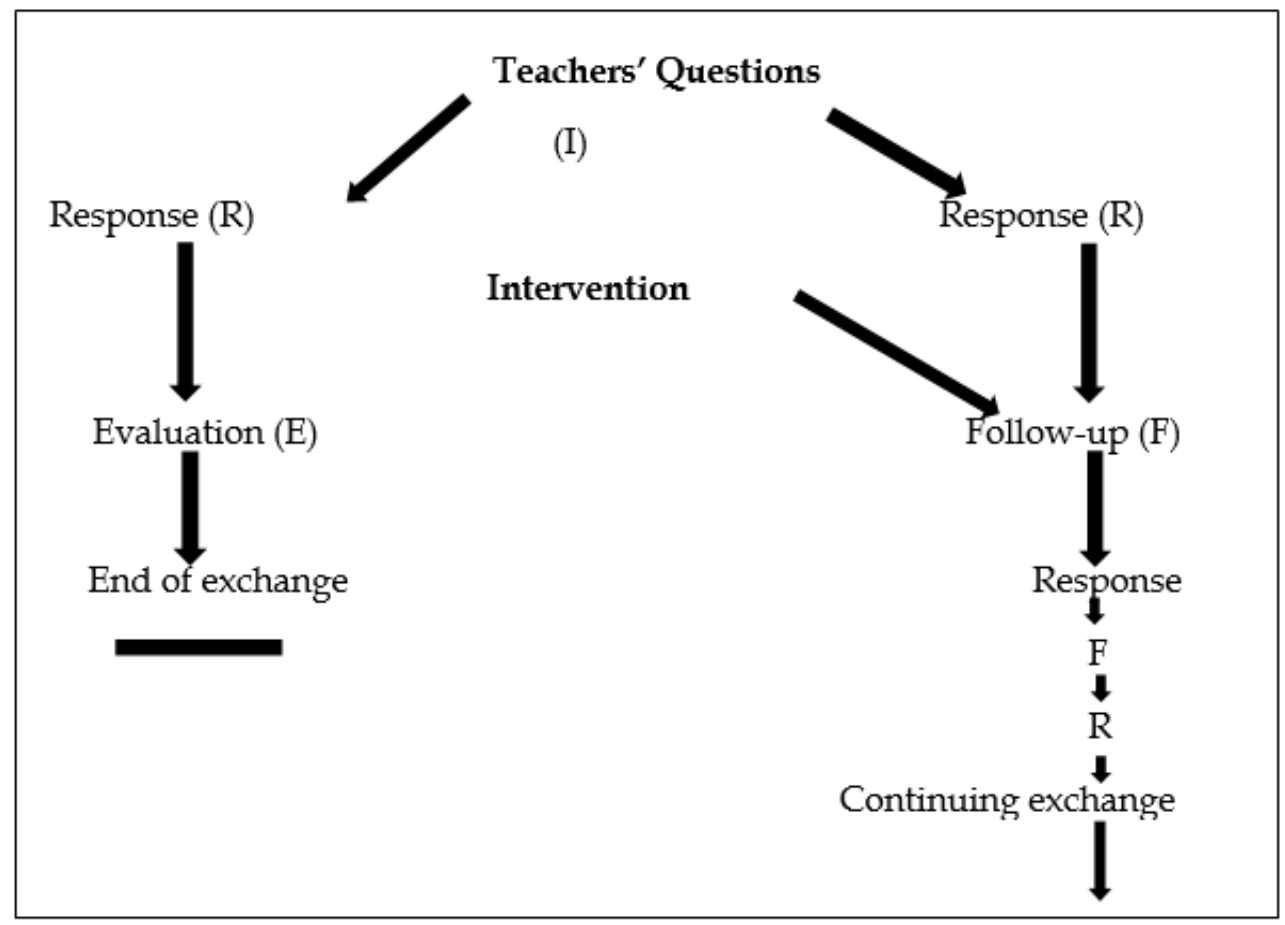

Figure 1: Conceptual framework of the study 
This conceptual framework explains that classroom interaction can move in two directions, initiated with teachers' questions. When the teacher gives an evaluation for the student's response, the interactional exchange is brought to an end. Instead, if the response is followed by a follow-up question, the exchange continues. Giving follow-up, in this study, was facilitated by an intervention. Hence, the following methodology was used to investigate the classroom discourse and answer the research questions.

\section{Methods}

This study follows a classroom action research method and the data were collected mainly through qualitative methods. Classroom discourse was the basis for data collection. The observed lessons were recorded and some selected lessons were transcribed. In addition, classroom observation, and teacher trainees' reflections obtained through individual discussions and their written answers for structural questions were used in this study.

\subsection{Participants}

The participants of this study were the final year TESL students who follow the TESL (Teaching English as a Second Language) degree with the Department of English Language Teaching (DELT) at the Faculty of Arts (herein after referred to as faculty). As part of the requirements of the course, the students have to undertake teaching practice at the faculty for 15 weeks in semester I of the fourth year of the degree programme. They are called Teacher Trainees (TTs) in this study. Of the twelve TTs in the academic year 2019/2020, four TTs were selected based on the convenience of the researcher for observation. These teacher trainees are in their early 20s and have studied in their mother tongue, Tamil, up to their GCE A/L ${ }^{1}$ (General Certificate in Education Advanced Level) and have studied English as a subject in their school from grade 3. Only those students with a good language proficiency are selected to the TESL degree each year. For three years, they have followed different courses in English language, linguistics and methodology in the medium of English. They have learnt the theoretical and practical aspects of teaching during their study.

For the teaching practice, the TTs are assigned to teach classes along with an instructor and observed by a senior lecturer. In this study, the researcher was the observer. Four TTs were selected based on the convenience of the researcher for observation and all of them were female students. In the batch there are eleven female students and only a male student and therefore the sample consisted of only female students. The TTs were assigned to teach a course in Elementary English to the first year Arts students. These first year students were just starting their academic studies in the university after studying English at their primary and secondary levels for 10 years. The students were grouped according to their language proficiency level from weaker to the best groups and these TTs were working with the top four groups out of eight.

${ }^{1} \mathrm{GCE} A / \mathrm{L}$ is the qualifying examination for university entrance 


\subsection{Observation}

A semester consists of 15 weeks and the observation took place at two stages, the first five weeks, followed by an intervention that lasted for four weeks and again the classes were observed for the last 5 weeks. Each teacher trainee was expected to teach around 30 hours of lessons for the semester, 2 hours a week. The ESL classes were held on Mondays and Tuesdays, and therefore the researcher was able to observe two TTs a week. Altogether four lessons were observed of each TT. In addition, the researcher maintained a field notebook to take down vital activities in the observed classroom for individual discussion with the TTs.

\subsection{Recordings and transcriptions}

All the observed lessons were recorded using smartphones which the TTs carried with them. The first lesson delivered by TTs was not taken into analysis for the reason that students would have behaved differently because of the presence of the researcher. From rest of the lessons, longest ones were selected. Two of the recorded lessons of each TT, before and after the intervention, one each, were transcribed using usual transcribing conventions by a colleague of the researcher. That is, altogether eight lectures were transcribed and the transcripts were compared with the recordings by the researcher.

The four TTs are identified as TTA, TTM, TTS, TTZ based on the first letter of their names along with TT. In addition, each of their two transcribed lessons were identified as 1 and 2 with their code names. No. 1 refers to the ESL lesson conducted before the intervention, while ' 2 ' indicates the lesson after the intervention. For example, TTZ 1 refers to the lesson conducted by TTZ before the intervention and TTZ 2 means the lesson after the intervention.

\subsection{Ethics}

At the faculty, where the study was conducted, the ethical guidelines are yet to be introduced. However, the informed consents were obtained from the four TTs and the researcher explained the purpose of the study to the students in the four groups. In addition, the dean of the faculty was informed about the study.

\subsection{Intervention}

An intervention was administered following the first part of the observation. The intervention focused on training the TTs to ask different types of questions that are useful for language development, mainly referential, as well as openended and closed questions during lessons. It also focused on interactional patterns that are developed by asking different types of questions. TTs were exposed to the discourse obtained from their own lessons conducted at the beginning (pre-intervention period) and exemplified how they maintained interactions and how they could have developed the interactions better in their lessons. Based on these reflections of their own lessons, changes were suggested. Hence, this process was participatory since the TTs themselves suggested how they could have progressed in the lessons, despite the fact that there were other constraints. 
The intervention was held for two hours a week for four weeks, followed by one week 'no observation week' for the TTs to get oriented themselves with the intervention and during the last five weeks they were observed again.

\subsection{Analysing the transcript}

The transcripts were analysed for questioning patterns, and interactional exchanges. The focus was on the IRE/F (follow-up) patterns developed before and after the intervention in each lecture. Student-initiated interactions were also checked for their availability but there was not any in any lesson discourse.

In this study, the teacher-student interactional exchanges were the important analytical components. Therefore, in analysing the lecture discourse, the following two components were paid attention. 1. Questions asked by the TTs: they are important because they make the initiation move. 2. Interactional exchanges: they are the key component of analysis. Following $\mathrm{Hu}$ and $\mathrm{Li} \mathrm{(2017)}$ and $\mathrm{Hu}$ and Duan (2018), any utterance identified as interrogative, imperative, or declarative which elicited a verbal response was considered a question (Navaz, 2020).

Then at the next stage, those questions that built into interactional exchanges ${ }^{2}$ or episodes ${ }^{3}$ were considered irrespective of the length of the exchanges and their numbers were counted. A colleague of the researcher assisted in the identification of questions. These questions that initiated interactions were categorised into two types: display and referential questions. Display questions require answers which are already known to the teacher, while referential questions request information from the students which is not known to the teacher (Brock, 1986, as cited in Navaz, 2020). All the others were put into the category of others. In addition, the TTs were requested to reflect on their own lecture delivery.

\subsection{Reflection of TTs}

The TTs were asked to comment on their own lesson delivery, important activities, etc. The researcher picked the vital points for clarification with the TTs from the field notebook. Some of the things that were clarified were the reasons for teacher questioning and their classroom discourse patterns at each stage of the lesson delivery. That is, their concerns and constraints in making classes interactive were also found out. The reasons for TTs and students' behaviours in lessons were also focussed on. In addition, the TTs were given some structured questions to write their views. For example, they were asked about the reasons for lack of classroom interaction.

\section{Findings}

In this section, mainly the following research questions are answered:

RQ1. What types of interactional episodes do the teacher trainees develop before the intervention in the undergraduate ESL classes at the faculty and what are the underlying reasons?

\footnotetext{
${ }^{2}$ Question-answer-feedback/evaluation is known as an exchange. Usually a teacher question, student response and teacher feedback (e.g. can you explain further) or evaluation (e.g good)

${ }^{3}$ One or several exchanges that occur at one point in a lesson make an episode.
} 
RQ2: What impact does the intervention have on classroom discourse of ESL classes conducted by the TTs and what are the underlying reasons?

Before answering the first research question, some background details that are connected with those research questions are presented.

\subsection{Summary of the lessons}

The lessons at the pre-intervention stage focused on parts of speech such as nouns, adjectives, adverbs, etc., while at the post-intervention stage they focused on present simple and continuous tenses.

\subsection{Identification of lessons transcribed before and after the intervention}

The table below (Table 1) indicates the lessons transcribed before and after the intervention and they are identified using TTs' code. Altogether eight lessons were transcribed and taken into analysis. Those lessons are TTA 1, TTA 2, TTM 1 and TTM 2, which are, for example, delivered by TTA and TTM respectively.

Table 1: Identification of lessons transcribed

\begin{tabular}{l|l|l}
\hline TTs & $\begin{array}{l}\text { Transcribed lessons } \\
\text { before the intervention }\end{array}$ & $\begin{array}{l}\text { Transcribed lessons } \\
\text { after the intervention }\end{array}$ \\
\hline TTA & TTA 1 & TTA 2 \\
\hline TTM & TTM 1 & TTM 2 \\
\hline TTS & TTS 1 & TTS 2 \\
\hline TTZ & TTZ 1 & TTZ 2 \\
\hline
\end{tabular}

Following this description, the first research question has been answered.

\subsection{Types of interactional episodes}

All kinds of interactional episodes were counted before and after the intervention. A series of interactional exchanges that occurred at a time were counted as a single episode. To say simply, a dialogue between teacher and students at a point of time is considered an episode. An episode can contain either single or a series of exchanges with IRE/IRF sequences. When the teacher returns to monologic talk or asks students to do some activity, the interactional exchange/episode ends. In this study, the interactional exchanges/episodes are called episodes and IRE refers to shorter single episode which has three moves and ends with evaluation, while extended IRF denotes longer episodes with several moves extended by follow-up questions or prompts.

Table 2: Types of interactional episodes and their number before the intervention

\begin{tabular}{lcl}
\hline TTs & $\begin{array}{l}\text { No. of IRE } \\
\text { interactional } \\
\text { episodes }\end{array}$ & $\begin{array}{l}\text { No. of extended IRF } \\
\text { interactional } \\
\text { episodes }\end{array}$ \\
\hline TTA & 15 & 00 \\
\hline TTM & 09 & 00 \\
\hline TTS & 17 & 01 \\
\hline TTZ & 18 & 02 \\
\hline Total & 59 & 03 \\
\hline
\end{tabular}


The number of interactional episodes found in the analysed lecture discourse of the four TTs are given in Table 2. They were limited in number and altogether there were 62 of them. Further, 59 of the total interactional episodes belonged to the IRE pattern. An example of an IRE sequence is given in Extract 1. The evaluation usually given in the lessons are 'very good', 'good', 'OK', 'fine', etc. Across the lessons, OK was more prevalent. We have already seen that when the evaluation is given in the third move, the interactional episodes have been brought to a stop. This makes a typical IRE episode. Then, the TTs asked another question or got on with explaining the lesson.

Extract 1: Example of IRE pattern of discourse (from TTA's lesson)

T: The park has a big pond. In this sentence, what are the nouns? - I

S: Park and pond. - $\mathrm{R}$

T: Park and pond. OK. - E

[[Transcribing conventions used: T- Teacher, S, S1, S2 ... students]]

In addition, on three occasions the extended pattern of IRF sequences were produced by TTS and TTZ. For example, in a lesson conducted by TTS, the TT used follow-up questions to sustain the interaction. She avoided giving evaluation, instead used a follow-up question to continue the interaction, as shown in Extract 2 below.

\section{Extract 2: Example of IRF pattern of discourse (From TTS's lesson)}

T: Today we are going to study about TV programs and shows. Do you have a habit of watching TV in your life? Everyone please respond. Do you have a habit of watching television or dramas or movies? I

S1: Yes miss.

$\mathrm{R}$

T: Now tell me what are the TV programs that are being telecasted on TV? There are many varieties of programs telecasted there no? Ok fine. Let me explain it. $\quad$ F Follow-up

$\mathrm{T}$ : Have you all understood what is documentary?

S1: Yes miss. $\mathrm{R}$

T: Have you all understood what is sitcom? F

S: A situational comedy. [[many students answer]] $\mathrm{R}$

T: Yeah comedy program. The characters are real life characters or fictional characters? $\mathrm{F}$

S2: Fictional characters. S

T: Do you all like any dramas? or you used to watch any dramas in your life? What is your favourite drama? Have you ever watched any serials?

[[the dialogue continues...]]

The reasons for generally producing limited number of interactional as well as shorter episodes were revealed by the TTs. One is that the TTs tried to push through the lesson and wanted to cover the whole materials in the lesson within the allocated time. Other one is that they were anxious in the class because the supervisor and an instructor were observing their lessons so they were hesitant to get involved in a dialogue with the students because they feared they might get stuck or use wrong forms of language while getting involved in interaction. 
TTA said, "we are afraid that we need to finish the lesson on time and have to cover all the contents of the allocated modules. Sometimes, supervisors think that we are idling in the class by asking questions." The tendency to getting through and moving on with the lesson was reported in the Skinner (2019) where the teacher trainees did not want to prolong the interaction but they wanted to continue with the lesson.

Moreover, the TTs did not have an idea of the pattern of interaction they produced in the lessons. Mostly, the TTs produced IRE pattern because for them interaction was a question-answer-appreciation (evaluation) sequence.

It emerged from the study that another reason for developing IRE pattern could be connected to the types of questions. When TTs initiated the interaction with the display questions, the interaction usually followed the IRE pattern. As shown in Table 3, more than $75 \%$ of the questions produced in the lessons are display questions. In Skinner's study (2019), when the teacher trainees initiated display questions they could not develop longer interactional episodes. Skinner describes, "display questions are less likely to open up interaction than referential questions and as with the IRF move, can be used by teachers to constrain interaction, and, in effect, confine learner contribution" (ibid: p. 4). This situation is similar in this faculty too. The reasons for triadic dialogue pattern of IRE may be because of the display questions asked by the TTs.

Table 3: Types of questions before the intervention

\begin{tabular}{|c|c|c|c|c|}
\hline \multirow[t]{2}{*}{$\begin{array}{l}\text { Types of Questions in } \\
\text { the 'I' move / TTs }\end{array}$} & \multicolumn{4}{|c|}{$\begin{array}{c}\text { Before the intervention (\%) } \\
\text { (found in a single lesson of each TT) }\end{array}$} \\
\hline & TTA & TTM & TTS & TTZ \\
\hline Display & $61(86 \%)$ & $30(77 \%)$ & $97(79 \%)$ & $67(81 \%)$ \\
\hline Referential & 00 & 00 & $03(02 \%)$ & $05(06 \%)$ \\
\hline Others & $10(14 \%)$ & $09(23 \%)$ & $23(19 \%)$ & $11(13 \%)$ \\
\hline Total & 71 & 39 & 123 & 83 \\
\hline
\end{tabular}

The TTs, especially TTZ and TTS who produced longer interactional episodes were asked about how they could produce extended sequences of interaction using IRF pattern but they described it as incidental. That is, they did not plan to have longer interactional episodes but it occurred during teaching.

With these details of the pattern of interaction found in the lessons before the intervention and discussing the underlying reasons, mainly for the pattern of discourse, the second research question is answered.

RQ2. What impact does the intervention have on classroom discourse of ESL classes conducted by the TTs and what are the underlying reasons for the patterns of interactions?

In this part of the findings, I compare the situation before and after the intervention under the title "outcome of the intervention." 


\subsection{Outcome of the intervention}

As a result of the intervention, two things were envisaged to occur in the lecture discourse of TTs. One is that the TTs needed to ask more number of referential questions and more importantly, they needed to maintain lengthy interactional exchanges that used IRF sequence with follow-up moves.

\subsubsection{Types of questions}

It was obvious from the findings that most of the questions asked by the TTs were display type questions. However, there was a slight increase in the number of referential questions asked by a TT (TTZ) after the intervention, as shown in Table 4. It was shown already that display questions warrant an answer which is already known to the questioner, usually the teacher, while referential questions request information from the respondents which is not known to the teacher. Teo (2016) found that teachers asked more display type questions in a preuniversity programme in Singapore that prevent them from developing longer interaction. Teo (2016) further argued that display questions seem to extract predetermined answers that the teacher is looking for, thereby constricting the space for reflection, question and dialogue, leading to confined interactional exchanges. Cullen (2002) and Skinner (2019) exemplified that display questions are less likely to open up interaction than referential questions.

It was further revealed that only after the intervention the TTs had got a clear understanding of the fact that referential questions are useful for language development compared to the display questions. Moreover, the reflection of their own lessons during the intervention stage was more useful for them to get an awareness of their own questioning pattern and the desirable types of questions.

Table 4: Types of questions before and after the intervention (parenthesis indicates \%)

\begin{tabular}{|c|c|c|c|c|c|c|c|c|}
\hline \multirow{2}{*}{$\begin{array}{l}\text { Types of } \\
\text { Questions in } \\
\text { the 'I' move } \\
\text { // TTs }\end{array}$} & \multicolumn{4}{|c|}{ Before intervention (\%) } & \multicolumn{4}{|c|}{ After intervention (\%) } \\
\hline & TTA & TTM & TTS & TTZ & TTA & TTM & TTS & TTZ \\
\hline Display & $\begin{array}{l}61 \\
(86 \%) \\
\end{array}$ & $\begin{array}{l}30 \\
(77 \%)\end{array}$ & $\begin{array}{l}97 \\
(79 \%) \\
\end{array}$ & $\begin{array}{l}67 \\
(81 \%)\end{array}$ & $\begin{array}{l}60 \\
(92 \%)\end{array}$ & $\begin{array}{l}28 \\
(82 \%)\end{array}$ & $\begin{array}{l}90 \\
(80 \%)\end{array}$ & $\begin{array}{l}90 \\
(84 \%)\end{array}$ \\
\hline Referential & 00 & 00 & $\begin{array}{l}03 \\
(02 \%)\end{array}$ & $\begin{array}{l}05 \\
(06 \%)\end{array}$ & $\begin{array}{l}01 \\
(02 \%)\end{array}$ & 00 & $\begin{array}{l}04 \\
(04 \%)\end{array}$ & $\begin{array}{l}11 \\
(10 \%)\end{array}$ \\
\hline Others & $\begin{array}{l}10 \\
(14 \%)\end{array}$ & $\begin{array}{l}09 \\
(23 \%)\end{array}$ & $\begin{array}{l}23 \\
(19 \%)\end{array}$ & $\begin{array}{l}11 \\
(13 \%)\end{array}$ & $\begin{array}{l}04 \\
(06 \%)\end{array}$ & $\begin{array}{l}06 \\
(18 \%)\end{array}$ & $\begin{array}{l}18 \\
(16 \%)\end{array}$ & $\begin{array}{l}06 \\
(06 \%)\end{array}$ \\
\hline Total & 71 & 39 & 123 & 83 & 65 & 34 & 112 & 107 \\
\hline
\end{tabular}

Of the questions asked by the TTs, some were one word questions/prompts like next?, then?, why?, etc. In addition, there were some classroom procedural questions too. E.g. Did you attend the last class? and clarification requests. A clarification request is a direct form of question or request to clarify the preceding utterance of the other speaker (e.g. 'Beg your pardon' in TTS1; 'Miss, repeat the answers' in TTZ1), while a confirmation check is made to ensure that what is heard by the other speaker is correct. The latter is usually made by repetition of all or part of the other's preceding utterance through rising 
intonation questions (Long, 1981). These types of questions are put under the category 'others.'

\subsubsection{Number of interactional episodes developed}

All kinds of interactional episodes that occurred before and after the intervention are given in Table 5.

Table 5: Number of interactional episodes developed before and after the intervention

\begin{tabular}{lll}
\hline TTs & $\begin{array}{l}\text { No. of interactional } \\
\text { episodes before the } \\
\text { intervention }\end{array}$ & $\begin{array}{l}\text { No. of interactional } \\
\text { episodes after the } \\
\text { intervention }\end{array}$ \\
\hline TTA & 15 & 19 \\
\hline TTM & 09 & 11 \\
\hline TTS & 18 & 23 \\
\hline TTZ & 20 & 21 \\
\hline
\end{tabular}

According to this table, the number of interactional episodes, developed in the observed two lessons, are limited in number. However, the higher number of interactional episodes does not mean that the interactional episodes were longer and useful for language development. The pattern of interactional exchanges only would tell us if the episodes are useful for language development. In the post intervention lessons conducted by TTS and TTZ, many of the questions were not answered by the students and they passed as rhetorical questions which expect no answer from the students or were answered by the TTs themselves. The reasons for not answering questions by the students could vary. TTs after asking questions, had to give enough wait-time, repeat the questions or nominate a student to answer the questions. These measures made the students answer the questions to a certain extent. In the observed classes, TTZ had used some of these strategies to make the students answer. In addition, students' shyness, anxiety or lack of language proficiency would also prevent students from answering the questions. Further discussion on this is given under the discussion section.

\subsubsection{Patterns of interaction}

Two patterns of interactions were looked into, shorter IRE pattern with evaluation and or an extended IRF pattern with follow-up moves. Earlier, Table 2 indicated the patterns of interaction before the intervention and they are given here again for a comparison. As shown in Table 6 below, even after the intervention most of the interactional exchanges followed the IRE pattern. That means the TTs usually gave an evaluation at the third move and brought the interaction to an end.

Table 6: Patterns of interaction before and after the intervention

\begin{tabular}{lllll}
\hline \multicolumn{2}{c}{ Before the intervention } & \multicolumn{2}{c}{ After the intervention } \\
\hline TTs & $\begin{array}{l}\text { No. of IRE } \\
\text { interactional } \\
\text { episodes before } \\
\text { the intervention }\end{array}$ & $\begin{array}{l}\text { No. of extended IRF } \\
\text { (follow-up) }\end{array}$ & $\begin{array}{l}\text { No. of IRE } \\
\text { interactional } \\
\text { episodes before the } \\
\text { intervention }\end{array}$ & $\begin{array}{l}\text { No. of extended IRF } \\
\text { the intervention after } \\
\text { (follow-up) } \\
\text { interactional } \\
\text { episodes after the } \\
\text { intervention }\end{array}$ \\
\hline TTA & 15 & 00 & 19 & 00 \\
\hline
\end{tabular}




\begin{tabular}{lllll}
\hline TTM & 09 & 00 & 11 & 00 \\
\hline TTS & 17 & 01 & 21 & 02 \\
\hline TTZ & 18 & 02 & 14 & 07 \\
\hline
\end{tabular}

Here, the expectation was that after the intervention there would be more extended IRF patterns and lower IRE patterns. But, there wasn't much improvement in the way TTs handled interactions. Except TTZ and TTS, the other TTs did not use the extended pattern. In the case of TTA and TTM, none of the episodes followed the IRF pattern. TTZ showed some improvement in her delivery. An example from the lesson TTZ 2 (Extract 3) is given below where TTZ and students involved in a dialogue which used longer students' responses.

\section{Extract 3: From TTZ 2 (T: TT; S1, S2 - students)}

T: Can anyone say (tell) the summary of today's lesson? What did we study today? I

S1: About used to. $\mathrm{R}$

T: yeah we studied about 'used to' and 'didn't use to' ok? When do we use used to? E $+\mathrm{I}$

S1: We use 'used to' to describe something happened in the past. But not now. $\quad R$

T: Yeah very good. To describe something which happened regularly in the past but it doesn't happen now. ok then the structure? How do we use used to (in) affirmative sentence? E + F (follow-up)

S2: Sub+ used to+ didn't use to + verb. $\quad \mathrm{R}$

T: Ok. Actually, the subject + used to + verb. Ok then how do we use used to in negative sentences? can you all tell me the structure? E + I

S2: Sub+ didn't use to + verb. R

$\mathrm{T}$ : Very good. Then? $\mathrm{E}+\mathrm{F}$

S1: Question form is, did +sub+ used to + verb. R

T: Very good ok fine. E

In this extract, TTZ by asking follow-up questions in addition to evaluation continues the interaction. She initiates connected questions or uses a prompt like 'then' to signal the students to continue their utterances. When she wants to stop the interaction she uses 'ok' and 'fine', which are treated to be evaluations and the exchange is brought to an end. On many occasions, the TTs asked display questions and the interactional exchanges were shorter, where the third moves are not available, as shown below in extract 4 .

\section{Extract 4: from TTA 1}

$\mathrm{T}$ : What is the last month of the year? I

$\mathrm{S}_{1}$ : December. $\mathrm{R}$

$\mathrm{T}$ : What is the month after June? I

$\mathrm{S}_{2}$ : July. $\quad \mathrm{R}$

Similarly, in other lessons from TTA1 and TTS 2 students gave short answers as given in extract 5 . In these examples, TTS asks display type questions too for which students tend to answer in a single word.

\section{Extract 5: from TTS 2}

$\mathrm{T}$ : What is there on the screen? I

$\mathrm{S}$ : Headline news. $\mathrm{R}$

T: What is news? I 


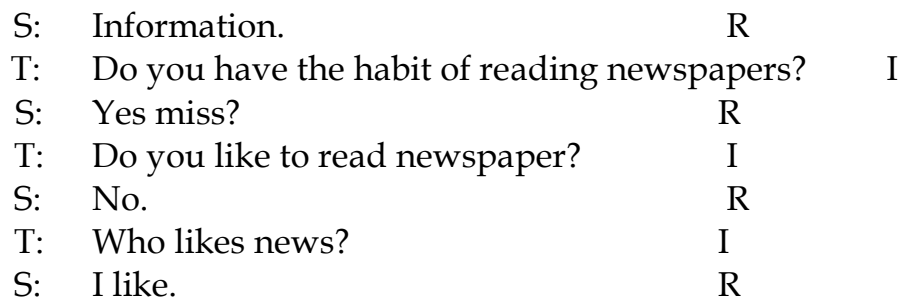

It is also alleged that when the teachers use open-ended questions, the interaction would be longer. For example, in another lesson when TTZ asked an open-ended question which required a lengthy answer, student tried to use longer utterances. In TTZ's move, an evaluation for the previous utterance precedes an initiation, as shown in Extract 6.

\section{Extract 6: from TTZ 2}

TTZ: Can you tell me all the pictures in order? I

$\mathrm{S}$ : First one is the welcome poster. Second one is about the music...... $\mathrm{R}$

These findings indicate that when the TTs used referential or open-ended questions, the students attempted to answer in longer utterances, whereas when the TTs used display questions, students answered in a single word. Brock (1986) and Musumeci (1996) consider that it is important to have open-ended questions to generate a greater interaction, and Morell (2004) in a similar vein argues that referential questions, which are open-ended, bring more contributions from students.

\subsubsection{The underlying reasons for the pattern of interaction}

Several reasons were discussed and of them some important ones are given below such as TTs' lack of knowledge on question types and interactional patterns, students' cooperation, students' language proficiency, TTs' time constraint and anxiety to develop interaction. Some of these reasons were discussed earlier in this section.

The TTs while acknowledging the fact that they lacked awareness on question types and the extended interactional exchanges are limited in their lessons, stressed that students' cooperation was important.

TTZ mentioned:

"The main thing we have to understand in order to maintain the interaction is to identify their capacity and needs"

"Sometimes it's our unawareness and in few instances students' support. Also, in some situations we don't know how to interact quickly to (with) the students."

TTS reflected that she was happy with the way the interaction occurred in her class. She stated: "in my class I am trying my level best to maintain a good rapport in order to develop interaction with the students." Nevertheless, there were plenty of IRE patterns across her lectures. When she was indicated it, she agreed that she needed to improve the pattern of interaction in the future. 
TTA's claim was that the students did not cooperate to maintain interaction in lessons. She mentioned: "I felt that even though we named students in asking questions, they keep silent (quiet) and also in some instances they acted like they didn't hear the teacher."

TTZ who had a few longer interactional episodes in her discourse mentioned that only after the intervention she realized the importance of maintaining longer interactional exchanges. She too had the similar opinion about the students that they did not cooperate. She states:

"In my point of view, I felt that student's support is more important for the successful interaction in the classroom. As I asked feedback from my students at last, they told me that the lecture was interesting. At the same time some of the students remained silent when asked some questions. Only some of the students who regularly talk answer the questions. According to it, it's very hard for us to conduct the lectures in an interactive manner."

As a whole, the TTs are of the opinion that students' support is important for developing interaction, albeit they agreed that they have to put more effort in the future with more awareness of the importance of developing interaction and the know-how of doing it.

\section{Discussion}

The discussion section should be considered with the limitations of the study when it comes to interpreting the results of the study. The participants in the study were teacher trainees in their final year of their study and should be treated as novice teachers and only four of them were involved in the study. In addition, only two lessons of each TT were taken into analysis, one before the intervention and one after the intervention.

The findings of this study confirmed that before the intervention the interactional exchanges developed were similar to the recitation scripts (Tharp \& Gallimore, 1988) in which one-to-one question, answer, evaluation or feedback patterns existed. More importantly longer interactional exchanges were absent throughout the majority of the lesson discourse. The TTs asked more display questions and most of the time students answered in one or two word utterances. Skinner (2019) explains that IRF pattern (or the three-part exchange) is preferred by teacher trainees because they think it is a safer option that it gives less interactional space to the real learners, so that trainees need not answer any unexpected questions from learners. Similarly, in the findings of this study it was mentioned that the TTs did not spend much time in developing interactions so that they wanted to teach the whole content of the lesson. These findings were similar to Skinner's (2019) findings.

It could be noticed that after the intervention there was a slight change in the way interactional exchanges were handled, especially two TTs have shown slight improvement in maintaining longer interactional exchanges where students' responses were also longer. Based on the reflection of the TTs, we can maintain that the presence of longer interactional exchanges was the results of the intervention even though individual abilities of the TTs could also influence 
as discussed below. The TTs also confirmed that only after the intervention they came to know the importance of maintaining interactional exchanges, especially longer and meaningful interactional exchanges. However, substantive evidence should be collected via future research with more samples to prove that intervention has an impact on the classroom discourse pattern. It is also noteworthy that longer interactional episodes would not always help language development.

The reasons for the present pattern of interaction were revealed by the TTs that they were unaware of the importance of interaction, and also they reported that students' cooperation with classroom interaction was poor. In addition, TTs, being novice teachers, were unable to control and develop interaction successfully. The language proficiency of the students and their usual reluctance in classroom participation including shyness would also hamper their active participation in involving in teacher-student interaction in ESL classes. Generally, students in the Asian region are shy to talk in classes irrespective of their language proficiency. A previous study by the researcher in tertiary level content classes (Navaz, 2012; 2013) revealed that students felt asking or answering questions in classes was not appropriate. They would rather ask any questions in private if they had.

Of the four TTs, only one (TTZ) had shown a slight improvement in maintaining the pattern of interaction towards extended patterns. The reasons for this nature could be connected to the individual abilities of the TTs too. TTZ was a high performer in the class and her language ability and the confidence she handled the classes with seem to be relatively higher. Previous studies have established that the success of developing longer interactional episodes depends on the personality of the teachers and their language proficiency. For example, Samaranayake (2016) found that the teachers' ability to develop and sustain oral activities influenced the classroom interaction. Similarly, teachers' language proficiency is important for effective teaching. Even though TTZ whose language proficiency is higher compared to others had developed longer interactional exchanges using referential and open-ended questions, further evidence may be required through future research studies to make the claim that teachers' personality and language proficiency influence the classroom interaction.

This study also informs us that teachers should be aware of the importance of asking questions in ESL classes and gain the expertise needed for asking openended referential questions and developing longer interactional episodes. More importantly, the teacher should be trained to handle to sustaining longer interactional episodes in classes. Smith and Higgins (2006) explain that it may not be the quality of the original question which determines subsequent students' participation, rather the quality of the teachers' reaction to pupils' responses (the $\mathrm{F}$ move in the I-R-F exchange). This view endorses the view expressed by Nassaji and Wells (2000) who argued that if the teacher used a follow-up move instead of evaluation, the discourse develops further. The same view was previously expressed by Wells (1999) that follow-up move can give opportunity to extend student's answer. 
Despite its limitations, this study could be considered a precursor to the future studies that could deal with classroom discourse as a platform to develop the language proficiency of the students. In the absence of studies in South East Asia on using classroom discourse for developing language proficiency, the findings of this study can be important for teacher training programmes including the TESL degree programmes. Any such training programmes should incorporate the knowledge and practice of how to handle classroom discourse for language development successfully into their curricula.

\section{Conclusion}

This study investigated how the teacher trainees could develop longer and meaningful interactional episodes in their ESL lessons by manipulating the IRF sequence of interaction. Just like ESL classes in other contexts and countries, Sri Lankan tertiary level ESL classes also follow the IRE pattern of classroom discourse. Hence, an attempt made to bring changes into the way the teacher trainees developed and maintained interactional exchanges showed a slight change as a result of the intervention. This sheds light for future development in classroom discourse in terms of interactivity by training the ESL teachers to gain more experience and exposure to the techniques of controlling classroom discourse. This was found by Lee (2007) and Liu (2008) that teachers could be trained to use the IRF sequence productively in ESL classes. The TTs involved in the study were going to begin teaching as their career and were exposed to a limited amount of intervention and therefore drastic changes cannot be expected. Hence, they need to gain more experience to be able to control the classroom discourse. The findings of the study inform that more attention should be paid by ESL teachers for enhancing their knowledge of asking questions and maintaining interactions in ESL classes. In addition, future research is needed to find how the experienced teachers control the classroom discourse to sustain interaction. The proposed study should focus on providing more in-depth training to teachers in handling classroom discourse for language development and eliciting more data from lesson discourse.

\section{References}

Brock, C. A. (1986). The effects of referential questions on ESL classroom discourse. TESOL Quarterly, 20(1), 47-58. https://doi.org/10.2307/3586388

Boyd, M. P., \& Markarian, W. C. (2015). Dialogic teaching and dialogic stance: Moving beyond interactional form. Research in the Teaching of English, 49(3), 272-295. https:// doi:10.1080/09500782.2011.597861

Chang, F. (2009). How teacher questioning behaviours assist and affect language teaching and learning in EFL classrooms in Taiwan [PhD Thesis, University of Warwick]. http://webcat.warwick.ac.uk/record=b2282533 S9

Chin, C. (2007). Teacher questioning in science classrooms: Approaches that stimulate productive thinking. Journal of Research in Science Teaching, 44(6), 815-843. https://doi.org/10.1002/tea.20171

Cullen, R. (2002). Supportive teacher talk: the importance of the F move. ELT Journal, 56(2), 117-127. https://doi.org/10.1093/elt/56.2.117

Davidson, C., \& Edwards-Groves, C. (2020). Producing and closing down multipleresponse sequences during whole-class talk in an early years classroom. Language and Education, 34(3), 193-211. https://doi.org/10.1080/09500782.2019.1689995 
Edwards-Groves, C. (2014). Talk moves: A Repertoire of practices for productive classroom dialogue. PETAA Paper, 195, 1-12.

Gibbons, P. (2003). Mediating language learning: Teacher interactions with ESL students in a content-based classroom. TESOL Quarterly, 37(2), 247-273. https://doi.org/ $10.2307 / 3588504$

Gibbons, P. (2015). Scaffolding language, scaffolding learning: Teaching English Language Learners in the mainstream classroom ( $2^{\text {nd }}$ ed.). Portsmouth, NH: Heinemann.

Gupta, A., \& Lee, G. L. (2015). Dialogic teaching approach with English language learners to enhance oral language skills in the content areas. International Journal $\begin{array}{llll}\text { of Language } & \text { 10-17. }\end{array}$ https://digitalcommons.odu.edu/teaching-learning_fac_pubs/19

Hall, J. K. (1998). Differential teacher attention to learner utterances: The construction of different opportunities for learning in the IRF. Linguistics and Education, 9(3), 287-311. https://doi.org/10.1016/S0898-5898(97)90003-6

Hall, J. K., \& Verplaetse, L. S. (Eds.) (2000). Second and foreign language learning through classroom interaction. Mahwah, NJ: Lawrence Erlbaum.

Hall, J. K., \& Walsh, M. (2002). Teacher-student interaction and language learning. Annual Review of Applied Linguistics, 22, 186-203. https://doi.org/10.1017/S0267190502000107

Haneda, M. (2005). Some functions of triadic dialogue in the classroom: Examples from L2 research. The Canadian Modern Language Review/La Revue canadienne des langues vivantes, 62(2), 313-333. https:// doi.org/10.1353/cml.2006.0003

Haneda, M., \& Wells, G. (2010). Learning science through dialogic inquiry: Is it beneficial for English-as-additional-language students? International Journal of Educational Research, 49(1), 10-21. https:// doi.org/10.1016/j.ijer.2010.05.003

Hellermann, J. (2003). The interactive work of prosody in the IRF exchange: teacher repetition in feedback moves. Language in Society, 32(1), 79-104. https://doi.org/ 10.10170S0047404503321049

Hu, G., \& Duan, Y. (2018). Questioning and responding in the classroom: a crossdisciplinary study of the effects of instructional mediums in academic subjects at a Chinese university. International Journal of Bilingual Education and Bilingualism, 22(3), 303-321. https:/ / doi.org/10.1080/13670050.2018.1493084

Hu, G., \& Li, X. (2017). Asking and answering questions in English-medium instruction classrooms: What is the cognitive and syntactic complexity level? In J. Zhao \& L. Q. Dixon (Eds.), English medium instruction in Chinese universities: Perspectives, discourse and evaluation. (pp. 184-203). New York: Routledge.

Karunaratne, I. M. (2003, November 28-30). Teaching English in urban Sri Lanka: Some pedagogical issues. $9^{\text {th }}$ International Conference on Sri Lankan Studies, Matara, Sri Lanka.

Lee, Y. (2007). Third turn position in teacher talk: Contingency and the work of teaching. Journal of Pragmatics, 39(6), 1204-1230. https://doi.org/10.1016/j.pragma.2006.11.003

Lemke, J. L. (1985). Using language in the classroom. Deakin University Press.

Lemke, J. L. (1990). Talking science: language, learning and values. Norwood, NJ: Ablex.

Liu, Y. (2008). Teacher-student talk in Singapore Chinese language classrooms: A case study of initiation/response/follow-up (IRF). Asia Pacific Journal of Education, 28(1), 87-102, https://doi.org/10.1080/02188790701850071

Long, M. H. (1981) Input, interaction, and second language acquisition. In H. Winitz, (Ed.) Native Language and Foreign Language Acquisition (pp. 259-278). New York Academy of Sciences. 
Long, M. H. (1985). Input and second language acquisition theory. In S. M. Gass \& C. Madden, (Eds.) Input in Second Language Acquisition (pp. 377-393). Rowley, MA: Newbury House.

Mehan, H. (1979). Learning lessons: Social organization in the classroom. Cambridge, MA: Harvard University Press.

Mercer, N. (1995). The guided construction of knowledge: Talk amongst teachers and learners. Clevedon: Multilingual Matters.

Morell, T. (2004). Interactive lecture discourse for university EFL students. English for Specific Purposes, 23(3), 325-338. https:// doi.org/10.1016/s0889-4906(03)00029-2

Musumeci, D. (1996). Teacher-learner negotiation in content-based instruction: Communication at cross-purposes? Applied Linguistics, 17(3), 286-325. https:// doi.org/10.1093/applin/17.3.286

Nassaji, H., \& Wells, G. (2000). What's the use of triadic dialogue. Applied Linguistics, 21(3), 376-406. https://doi.org/10.1093/applin/21.3.376

Navaz, A. M. M. (2012). lecturer-student interaction in English-medium science lectures: an investigation of perceptions and practice at a Sri Lankan university where English is a second language [PhD Thesis, University of Nottingham]. http://eprints.nottingham.ac.uk/12995/

Navaz, A. M. M. (2013). A study on perception of lecturer - student interaction in english medium science lectures. Novitas - ROYAL (Research on Youth and Language), 7(2), 117-136. https://novitasroyal.org/download/a-study-onperception-of-lecturer-student-interaction-in-english-medium-science-lectures/

Navaz, A. M. M. (2020). Developing a framework for understanding lecturer-student interaction in English-medium undergraduate lectures in Sri Lanka: First step towards dialogic teaching. International Journal of English Linguistics, 10(6), 208229. https://doi.org/10.5539/ijel.v10n6p395

Perera, M. E. (2001). The role of classroom interaction in second language acquisition in Sri Lanka [Doctoral thesis, University of Wollongong, Australia]. http://ro.uow.edu.au/theses/1805

Quality Assurance Process - Peer Observation. (2020). Observation of ESL classes conducted by an Instructor.

Samaranayake, S. W. (2016). Oral Competency of ESL/EFL Learners in Sri Lankan Rural School Context. SAGE Open, April-June, 1-10. https://doi.org/10.1177/2158244016654202

Sanmuganathan, K. (2017). Historical perspective of English and some pedagogical problems and solutions in teaching English in Sri Lankan schools. International Journal of Scientific and Research Publications, 7(6), 623-629. http://www.ijsrp.org/research-paper-0617/ijsrp-p6678.pdf

Sinclair, J. M., \& Coulthard, M. (1975). Towards an analysis of discourse: The English used by teachers and pupils. Oxford University Press.

Skinner, B. (2019). 'Let's move on': second language trainee teachers' talk and its impact on learner interaction. The language learning journal. https://doi.org/10.1080/09571736.2019.1642371

Smith, H., \& Higgins, S. (2006). Opening classroom interaction: the importance of feedback. Cambridge Journal of Education, 36(4), 485-502. https://doi.org/10.1080/03057640601048357

Swain, M. (1995). Three functions of output in second language learning. In G. Cook \& B. Seidlhofer (Eds.) Principle and Practice in Applied Linguistics (125-144). Oxford University Press. 
Swain, M., \& Lapkin, S. (1998). Interaction and second language learning: Two adolescent French immersion students working together. The Modern Language Journal, 82(iii), 320-337. https:/ / doi.org/10.1111/j.1540-4781.1998.tb01209.x

Teo, P. (2016). Exploring the dialogic space in teaching: A study of teacher talk in the preuniversity classroom in Singapore. Teaching and Teacher Education. 56, 47-60. https:// doi.org/10.1016/j.tate.2016.01.019

Tharp, R. G., \& Gallimore, R. (1988). Rousing minds to life: Teaching, learning, and schooling in social context. Cambridge University Press.

University Grants Commission. (2018). Tracer study of graduates in Sri Lankan universities. Colombo: University Grants Commission.

Van Lier, L. (2001). Constraints and resources in classroom talk: Issues of equality and symmetry. In C. Candlin \& N. Mercer (Eds.) English language teaching in its social context: A reader (90-107). Routledge.

Walsh, S. (2011). Exploring classroom discourse language in action. Routledge.

Waring, H. (2009). Moving out of IRF (Initiation-Response-Feedback): A single case analysis. Language Learning, 59(4), 796-824. https:/ / doi.org/10.1111/lang.2009.59.issue-4

Wells, G. (1993). Reevaluating the IRF sequence: A proposal for the articulation of theories of activity and discourse for the analysis of teaching and learning in the classroom. Linguistics and Education, 5(1), 1-37. https://doi.org/10.1016/S08985898(05)80001-4

Wells, G. (1999). Dialogic inquiry: Towards a sociocultural practice and theory of education. Cambridge University Press.

Wells, G., \& Arauz, R. M. (2006). Dialogue in the classroom. Journal of the Learning Sciences, 15(3), 379-428. https://doi.org/10.1207/s15327809jls1503_3

Wood, D. (1992). Teaching talk. In K. Norman (Ed.), Thinking voices: The work of the national oracy project (203-214). Hodder \& Stoughton (for the National Curriculum Council).

Wong, J., \& Waring, H. Z. (2009). 'Very good' as a teacher response. ELT Journal, 63(3), 195-203. https:/ / doi.org/10.1093/elt/ccn042

Yip, D. Y. (2004). Questioning skills for conceptual change in science instruction. Journal of Biological Education, 38(2), 76-83. https:/ / doi.org/10.1080/00219266.20 